\title{
Influence of Some Demographic Factors on Infection of Schistosomiasis: The Case of Njombe-Penja Population, in the Littoral Region of Cameroon
}

\author{
Vincent Khan Payne, Sylvain Tathio*, Leonelle Megwi, Ghislain Roméo Ngangnang, Cedric Yamsi, \\ Cindy José Ouaba Tanefo, Vanessa Rosine Nkouayep
}

Department of Animal Biology, Research Unit of Biology and Applied Ecology, Faculty of Science, University of Dschang, Dschang, Cameroon

\author{
Email address: \\ SylvainPoulet89@yahoo.fr (S. Tathio) \\ ${ }^{*}$ Corresponding author
}

\section{To cite this article:}

Vincent Khan Payne, Sylvain Tathio, Leonelle Megwi, Ghislain Roméo Ngangnang, Cedric Yamsi, Cindy José Ouaba Tanefo, Vanessa Rosine Nkouayep. Influence of Some Demographic Factors on Infection of Schistosomiasis: The Case of Njombe-Penja Population, in the Littoral Region of Cameroon. Central African Journal of Public Health. Vol. 5, No. 3, 2019, pp. 113-119. doi: 10.11648/j.cajph.20190503.13

Received: January 25, 2019; Accepted: March 21, 2019; Published: April 26, 2019

\begin{abstract}
Schistosomiasis remains a major public health problem within Njombe-Penja population since the very first discoveries made in the sixties. Inadequate knowledge on both urinal and intestinal prevalences as well as socio-demographic influences of this infection in the whole area are some of the crucial factors for making faded epidemiological control of the disease. Between September 2014 and May 2015, according to a cross sectional study, 369 participants (172 males and 197 females) were randomly sampled where feces and urine samples were collected. Therefore they were respectively analyzed using the Kato-Katz and centrifugation techniques. Two species of schistosomes Schistosoma mansoni (19.8\%) and Schistosoma haematobium $(0.3 \%)$ with an overall prevalence of $20.1 \%$ were recorded. On the other hand, persons aged from 23 years $(5.7 \% ; \mathrm{P} \geq 0.05)$ and females $(10.3 \% ; \mathrm{P} \geq 0.05)$ were more infected. Furthermore, students $(14.7 \% ; \mathrm{P} \geq 0.05)$ and persons with primary school level of education were more infected as quarters crossed by streams such as Mbouale (5.4\%; P $\geq 0.05$ ) and Mouantaba (4.3\%; $\mathrm{P} \geq 0.05)$. However, mean parasitic load of intestinal schistosomiasis was 39.8 eggs/g of feces and $01 \mathrm{egg} / 10 \mathrm{ml}$ of urine for urinary schistosomiasis. This study reveals that, infection prevalence of schistosomiasis as well as parasitic load within Njombe-communities remain relatively high. While in socio-demographic influences, subjects with 23 and above, females, primary level of education, Mbouale and Mouantaba quarters had highest prevalence. Therefore, there is a huge need for integrated control program by treating the whole population.
\end{abstract}

Keywords: Demographic Factors, Schistosomiasis, Schistosoma Mansoni, Schistosoma Haematobium, Njombe-Penja

\section{Introduction}

Schistosomiasis is one of the neglected tropical diseases caused by the invasion of schistosome eggs in intestinal and vesical tissues of humans. When these eggs accidentally get outside, in aquatic environments edged by vegetation, they hatch and the emerged miracidia migrate toward a typical intermediate host, a snail [1]. It's within the snail tissues that immature stages take place after three weeks or even a month to finally produce the infective forms of the parasite, which is the furcocercaria. It's quite known that this infection causes less mortality but has considerable impact on socio-economic outcomes as well as the health status of individuals and communities. In fact, it was estimated that 200.000 persons lose their lives each year due to this infections [2]. Furthermore, it has been recorded that this parasitic disease causes mental retardation and Iron Deficiency Anemia in young subjects [3]. Since an aquatic environment is inescapable in the life cycle of the disease, riparian populations which are dependent on this resource to do culture, fishing and other water related activities have been incriminated as the most harmed populations by the infection $[4,5]$. In the world, out of 239 million persons suffering from 
this parasitic disease in $2009,85 \%$ lived in sub-Saharan Africa [6]. Specifically, about 112 million and 54 million are infected by urinary and intestinal forms respectively [7]. According to the World Health Organization in 2006 [8], the control of the disease should be based on morbidity control through chemotherapy with praziquantel; this should be adopted according to the epidemiological and geographical conditions of the study area since the pattern of infection varies from one area to other. In Cameroon, it was first revealed in 1972 that urinary schistosomisis is widely distributed in the Northern Region whereas only few foci were in the Southern part of the country. However, in this latest part, more precisely in the South-West Region of Cameroon most infections by urinary Schistosomiasis notably in riparian populations of Barombi Koto and Barombi Mbo have been recorded [5]. However in the Northern Region, the previous studies have revealed that rice growers and young subjects aged from 5 to 15 years are more susceptible to the disease [9]. The Littoral Region is another part of the country where the disease is prevalent. Anterior findings have shown that the population of Njombe has been infected by Schistosoma mansoni with prevalence of $13.07 \%$ of cases [10]; while up to $62.8 \%$ of population in Loum subdivision are reported to be infected by Schistosoma haematobium [11]. Beyond this, other researchers in Yemen and Ghana have reported that schistosomiasis infection is closely related to illiterate persons who do not know and practice hygiene and sanitation [12, 13]. Despite all these studies mentioned above in the Littoral Region of Cameroon, a real epidemiological picture of schistosomiasis within the entire population of Njombe-Penja Subdivision has not yet been implemented. The present study aims at assessing the influence of some socio-demographic parameters on the prevalence of schistosomiasis infections. Specifically, it seeks to evaluate the prevalence and the mean parasitic load of infection; evaluate the prevalence of infection in relation to age, sex, profession, quarter and level of education and determine the influence of demographic parameters on the mean parasitic load.

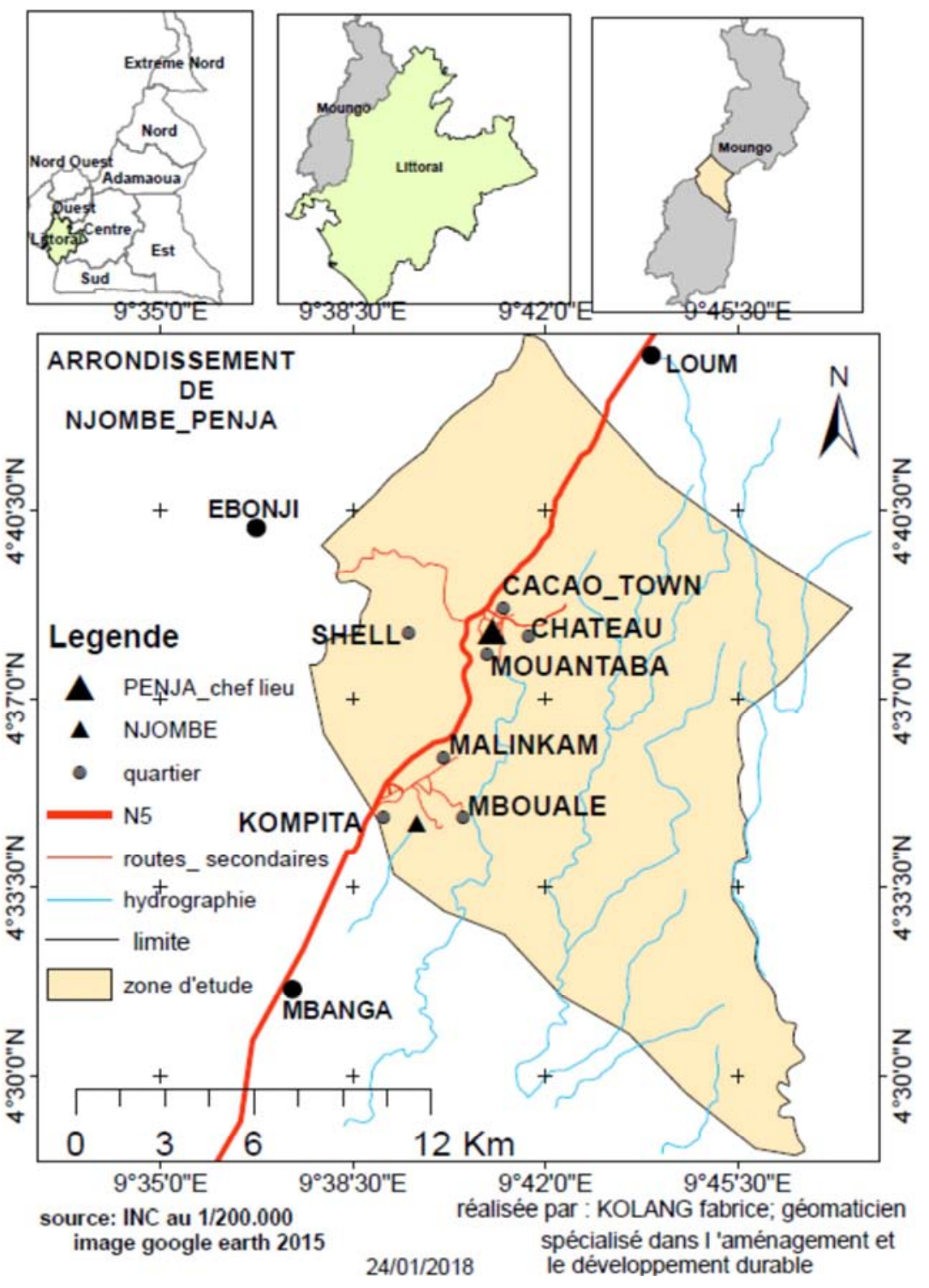

Figure 1. Map showing the localization area and collection points of data. 


\section{Methods}

\subsection{Study Area}

The study area Njombe-Penja (438'11"N; 9 $\left.400^{\prime} 55^{\prime \prime} \mathrm{E}\right)$ Sub-division is one of the 13 administrative units in Mungo Division, in the Littoral Region of Cameroon. This locality occupies a surface area of $391 \mathrm{~km}^{2}$ with 36,200 inhabitants. The landscape is dominated by rocky land, plain, plateau and hills while vegetation is mostly dominated by primary forest within which we encounter plantations of bananas, pineapples, pawpaw, cocoa, pepper and food producing. Here the annual precipitation is between 2000 to $2500 \mathrm{~mm}$ and it is well distributed throughout the year. The local thermal temperature is situated around $27^{\circ} \mathrm{C}$ [14]. The volcanic nature of the land and its physical properties favor the growth of plants. However, the economy of the locality is based on culture of cocoa, spices, and fruit plants. Besides, Haoussa, Mbo'o, Bamileke, Bafia, Beti and Bafung constitute the different local ethnic groups found in this area.

\subsection{Preliminary Study}

Before commencement, we organized a series of sensitization tours at different levels of the locality to inform the population about the study 2 weeks before. However, all private and public institutions, meeting and different selling telecommunication credit points as well as some road junctions were targeted to relay information about the future investigation.

\subsection{Study Quarters}

Seven quarters were involved in the study were seven in number. These quarters were chosen randomly from the list of all quarters that constitute the locality through a simple ballot method.

\subsection{Study Subject}

The study conducted between September 2014 and May 2015 was on 369 participants. This sample population was estimated through the Lorenz formula that is:

$$
N=\frac{\mathrm{Z}^{2} P Q}{\mathrm{~d}^{2}}
$$

However, these participants were made up of 172 males and 197 females aged from 3 years to 78 years and specially those who agreed to participate and met our inclusion criteria (to be resident of the locality, to be exempted of any vermifuge treatment, having the required age and have signed an informed consent form).

\subsection{Subject Consent}

The study was handled under the supervision of the Regional Delegate of Health of the Littoral Region, the Sub-
Divisional Officer of the Sub-Division and the Head of the District Hospital of Loum. All administrative authorities were informed and have gave their consent for the study to start. In addition, a written informed consent that met the standards of the National Ethical Commission was obtained from participants.

\subsection{Parasitological Study}

Both samples of feces and urine were collected in the field in two different $30 \mathrm{ml}$ screw-cap vials between 10 am to 14 $\mathrm{pm}$. Samples of feces were immediately conserve with $3 \mathrm{ml}$ of $10 \%$ formol [15], and urine with $1 \mathrm{ml}$ of sodium hypochlorite $(\mathrm{NaOcl})$ for $1000 \mathrm{ml}$ of urines [16]. Later on, these samples were transported to the Research Unit of Biology and Applied Ecology (URBEA) of the University of Dschang for examination. Indeed, stool samples were analyzed using the Kato-Katz concentration technique [17] while urine was analyzed by the centrifugation method.

\subsection{Data Analysis}

Data were recorded in manuscript into a register, and they entered into Microsoft Excel 2007. Later on, the data were transferred from Microsoft Excel to the software SPSS Version 22 for statistical analysis. Nevertheless, the Chisquare test was used to compare the prevalence in relation to age, sex, quarters, profession and level of education. The One way Analysis Of Variance (ANOVA) was used to compare the egg load in relation to age and sex. While, the level of statistical significance was at $95 \%(\mathrm{P}<0.05)$.

\section{Results and Discussion}

\subsection{Overall Prevalence}

From the 369 participants examined, 74 (20.1\%) were positive. Seventy three (19.8\%) of them had S. mansoni and only one case $(0.3 \%)$ had $S$. haematobium. The Figure 2 and Figure 3 below show eggs of these two species encountered during microcopy.

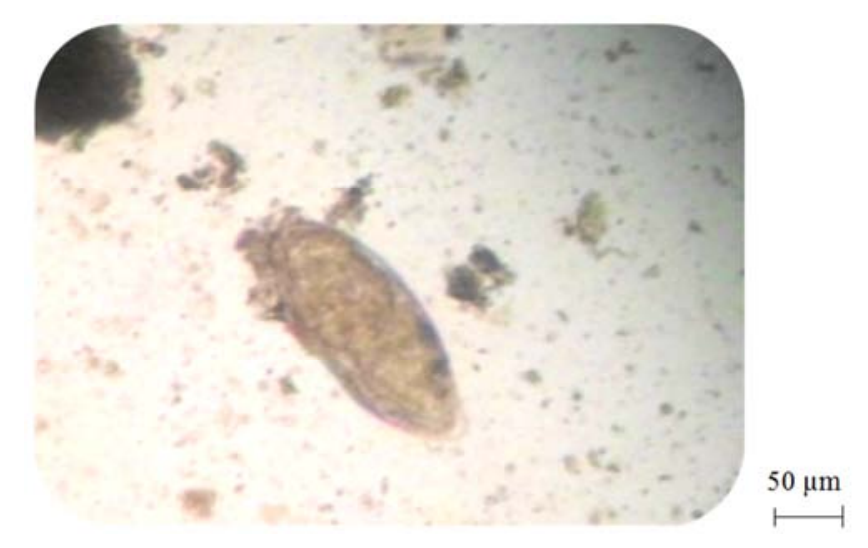

Figure 2. Schistosoma mansoni. 


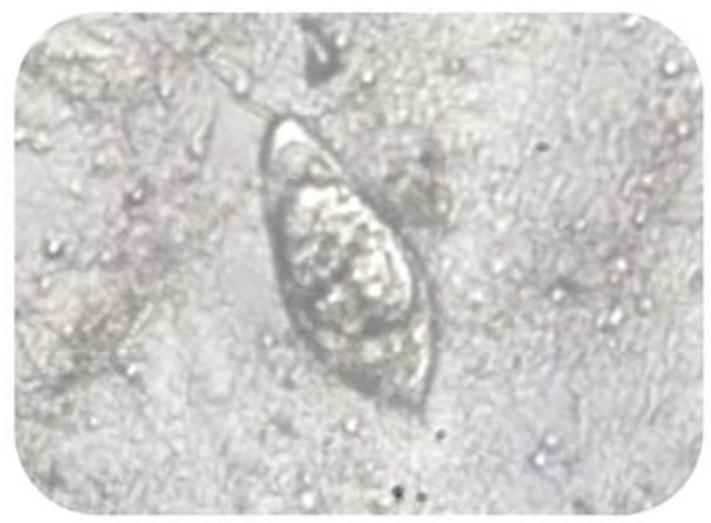

$40 \mu \mathrm{m}$

Figure 3. Schistosoma haematobium

The overall prevalence of $S$. mansoni infection of $19.80 \%$ corroborates with findings recorded in Bafia (18.6\%). On the other hand, these results are significantly low from those obtained in Melen focus in Yaounde (24.1\%) [18] and in the District of Mbita in Kenya (60.50\%) [19] With respect to $S$. haematobium infection the $0.3 \%$ obtained is somehow close to $0.9 \%$ (7/773) obtained in Djohong, in the Adamaoua Region in Cameroon but much lower $69.17 \%$ obtained in the Barombi Kotto focus in the South West Cameroon [5]. Whatever the case, the over-all relatively high prevalence of schistosomiasis infection $20.1 \%$ in our study may due to the regular treatment of this parasitic disease with praziquantel since the study site is historically known as endemic for this infection.

\subsection{Prevalence in Relation to Age}

Prevalence related to age revealed that participants of age 23 years and above and those of 8 to 12 years were the most infected with prevalence $5.7 \%$ and $5.2 \%$ respectively. However, the participants of age 18 to 22 years were less infected. The situation in each age group is highlighted in the Figure 4 below. However, statistical analysis revealed no significant difference $(\mathrm{P}>0.05)$ in the prevalence of infection with respect to age.

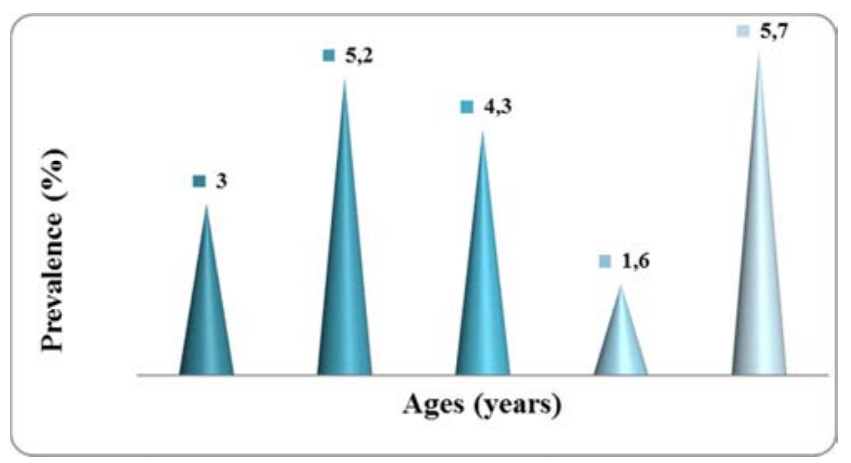

Figure 4. Prevalence of S. mansoni infection according to age groups.

The distribution of $S$. mansoni infection according to age group showed that participants aged from 23 years and above were the most affected. These results are a contradiction to those obtained in Nigeria and Kenya where more young persons aged from 9 to 12 years old were the most infected $[19,16]$. However, the predominance of these participants of age group 23 years and above may be due to the fact that they constitute a group less targeted for treatment compared to school age children who benefit from regular treatment based on praziquantel in their respective institutions [20].

\subsection{Prevalence According to Sex}

The pattern of infection in relation to sex, it was revealed that most females were infected by both $S$. mansoni $(10.3 \%)$ and $S$. haematobium $(0.3 \%)$ than males which were only infected by $S$ mansoni (9.5\%). However, this was not significant $(\mathrm{P}>0.05)$. Nevertheless, in the Figure 5 below, only the situation of $S$ mansoni infection is elucidated.

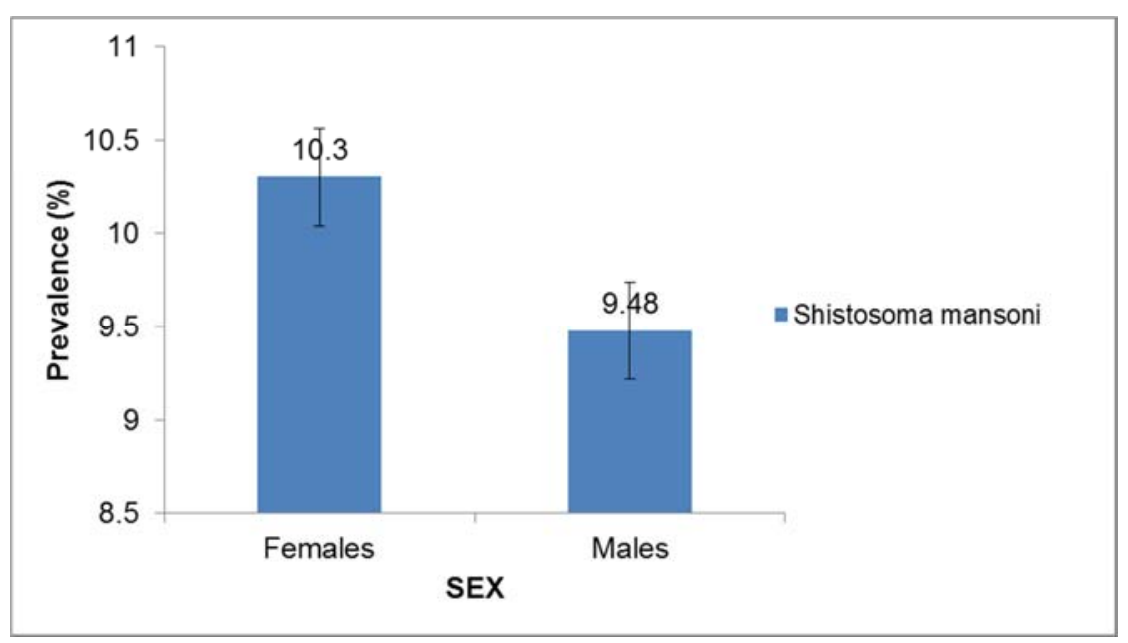

Figure 5. Prevalence of S. mansoni infection in relation to sex.

In a sex-related infection, we observed that, more females than males were infected. In similar studies, with such findings, attributions were allowed to female subjects than males [10]. However, these results contrast other observations which revealed that male subjects are more vulnerable than females due to male chauvinism and 
adventurism [5, 16]. Nevertheless, the sometimes high prevalence in females may be attributed to their frequent and somewhat daily involvement with water-contact activities such as washing linens, fetching wood, farming which bring them to long periods of exposure to water, a potential lodging site of furcocercaria larvae [21].

\subsection{Prevalence in Relation to Profession}

Table 1. Prevalence of S. mansoni infection related to profession.

\begin{tabular}{llll}
\hline Profession & $\begin{array}{l}\text { Number } \\
\text { examined }\end{array}$ & $\begin{array}{l}\text { Number } \\
\text { infected }\end{array}$ & Prevalence (\%) \\
\hline Farmers & 45 & 04 & 1.08 \\
Householders & 55 & 11 & 3 \\
Students & 229 & 54 & 14.63 \\
Teachers & 02 & 0 & 0 \\
Moto-riders & 16 & 04 & 1.08 \\
Civil servants & 20 & 0 & 0 \\
Unemployed & 01 & 0 & 0 \\
Mechanic & 01 & 0 & 0 \\
Total & 369 & 73 & 19.8 \\
\hline
\end{tabular}

The Table 1 above shows that students (14.63\%) were the most infected than householders $(3.00 \%)$ as well as Moto cycle riders $(1.08 \%)$ and Farmers $(1.08 \%)$. On the other hand no infection was recorded in other professions.

These results are similar to observations obtained in Mali during which the susceptibility of this group was highlighted [22]. On the other hand, they are in contradiction to other findings which showed farmers as the most affected group by the disease rather than non-farmers [23, 24]. However, the susceptibility of students recorded in the study may be due to their constant contact with doubtful water during their entertainment swimming, catching fish during warm periods of the day.

\subsection{Prevalence of $S$. Mansoni Infection Related to Residential Quarters}

Table 2. Prevalence of S. mansoni infection amongst quarters studied.

\begin{tabular}{llll}
\hline Quarters & $\begin{array}{l}\text { Number } \\
\text { examined }\end{array}$ & $\begin{array}{l}\text { Number } \\
\text { infected }\end{array}$ & $\begin{array}{l}\text { Prevalence } \\
(\%)\end{array}$ \\
\hline Kompita & 52 & 14 & 3.80 \\
Mbouale & 96 & 20 & $5.42^{*}$ \\
Moulinkam & 51 & 09 & 2.43 \\
Shell & 43 & 04 & 1.08 \\
Cacao-town & 22 & 08 & 2.20 \\
Château & 22 & 02 & 0.54 \\
Mouantaba & 83 & 16 & $4.33^{*}$ \\
Total & 369 & 73 & 19.80 \\
\hline
\end{tabular}

Among the seven quarters studied (Table 2) Mbouale $(5.42 \%)$ and Mouantaba (4.33\%) recorded relatively high rates of infection as compared to Kompita (3.80\%), Moulinkam (2.43\%) and Cacao-Town (2.20\%). Lastly, Shell $(1.08 \%)$ and Château $(0.54 \%)$ were those which presented few cases of infections.

This observation was similar to earlier reports done by [25] which revealed that populations living in proximity to rivers are more likely exposed to risk of infection. Moreover, this high prevalence encountered in these study sites may be due to the fact that, the rivers listed above which may be potential sites harboring snail vectors are more frequently used by the population to carry out daily domestic activities.

\subsection{Prevalence of S. Mansoni Infection in Relation to Level of Education}

Table 3. Prevalence of S. mansoni infection in relation to level of education.

\begin{tabular}{llll}
\hline $\begin{array}{l}\text { Level of } \\
\text { education }\end{array}$ & $\begin{array}{l}\text { Number } \\
\text { examined }\end{array}$ & $\begin{array}{l}\text { Number } \\
\text { infected }\end{array}$ & Prevalence (\%) \\
\hline Nursery & 05 & 01 & 0.30 \\
Primary & 186 & 40 & 10.84 \\
Secondary & 161 & 32 & 8.67 \\
Higher & 02 & 0 & 0.00 \\
Illiterates & 15 & 0 & 0 \\
Total & 369 & 73 & 19.80 \\
\hline
\end{tabular}

Table 3 above shows that persons with primary and secondary levels of education had infection rates of 10.84 and 8.67 respectively. Infection was absent in non school goers and those with higher education.

These results were in contradiction to what was found in Ghana where $46.20 \%$ of subjects without any level of education were infected in contrast to $20.50 \%$ who were somehow educated [26]. In Yemen, studies also portrayed that children whose parents didn't have a level of education were most infected (38.2\%) than those (25.8\%) whose parents had acquired only primary education [13]. Nevertheless, the predominance mentioned above may be explained by asserting that this category of persons was much represented by school age children who momentarily are in water for play since they are more active.

\subsection{Mean Parasitic Load}

Table 4. Mean parasitic load according to species.

\begin{tabular}{ll}
\hline Species & Mean parasitic load \\
\hline S. mansoni & 39.78 epg of feces \\
S. haematobium & $01 \mathrm{epg} / 10 \mathrm{ml}$ of urine \\
\hline
\end{tabular}

The mean parasitic load presented in Table 4 above showed that $S$. mansoni infection was quantified to $39.78 \mathrm{epg}$ of feces where only $01 \mathrm{egg} / 10 \mathrm{ml}$ of urine was recorded for S. haematobium.

This mean parasitic load (39.78 epg of feces) was below that recorded in Melen focus (248 epg of feces) in Yaounde [18]. On other hand, it is above the 1.72 epg of feces registered in Nigeria [16]. However, this mean parasitic load was close to that obtained in Ghana in the Kassana Nankana District (48 epg of feces) [26]. Whatever the circumstance, 39.78 epg of feces obtained revealed a case of slight infection. This situation may be explained by the fact that parasitological methods used to handle samples were less specific in an away to better appreciate the degree of infections.

\subsection{Effect of Age Group on the Mean Parasitic Load of S. Mansoni Infection}

According to age, participants aged 13-17 years old had 
the highest mean parasitic load (45.00 epg) followed those 18-22 years old (44.57 epg) and 3-7 years old (41.45 epg). Participants aged 23 years and above had $39.16 \mathrm{epg}$ and those 8-12 years old (33.60 epg) had the lowest parasitic load (Table 5). The mean parasitic load did not vary significantly withy age groups.

Table 5. Effect of age on mean parasitic load of S. mansoni.

\begin{tabular}{llllll}
\hline \multirow{2}{*}{ Species } & \multicolumn{4}{l}{ Age (years) } & \\
\cline { 2 - 5 } & \multicolumn{4}{l}{ Mean parasitic load (epg) } & \\
\hline \multirow{2}{*}{ S. mansoni } & $3-7$ & $8-12$ & $13-17$ & $18-22$ & $\geq 23$ \\
& 41.45 & 33.60 & 45.00 & 44.57 & 39.16 \\
\hline
\end{tabular}

These findings had been argued in others investigations during which higher parasitic loads instead observed in the age group 15-19 [27]. However, it may be due to the fact that these youths lodged a large number of adult worms having high fecundity rate in their system [28].

\subsection{Influence of Sex on the Mean Parasitic Load of S. Mansoni Infection}

Table 6. Influence of sex on mean parasitic load in S. mansoni.

\begin{tabular}{lll}
\hline \multirow{2}{*}{ Species } & \multicolumn{3}{l}{ Sex } \\
\cline { 2 - 3 } & Mean parasitic load (epg) \\
\hline S. mansoni & Females & Males \\
\hline & 42.95 & 36.34 \\
\hline
\end{tabular}

The influence of sex on the mean parasitic load of $S$. mansoni infection as it is highlighted in the Table 6 above, has shown that females (42.95 epg) were more infected than males (36.34 epg).

This Sex-related parasitic load distribution was also revealed in Ghana where 93.6 epg of feces and 60 epg of feces as mean parasitic loads were obtained in female and male subjects respectively [27]. On the other hand, in Melen, this was different as more male subjects showed higher loads 280 epg of feces than female ones (136 epg of feces) [18]. Whatever the case, the abundance of eggs recorded in females may be related to their behavior which tend to be in high contact with water during domestic chores.

\section{Conclusion}

The present investigation was designed to study the influence of some demographic factors on infection of Schistosomiasis in Njombe-Penja (Littoral Region of Cameroon). Even after a half century of their discovery in the locality, schistosomiasis remains endemic within this community. The study also revealed the dominance of $S$. mansoni as compared to $S$. haematobium. On the other hand, participants aged from 23 years old and above, female subjects, Mbouale quarter, students as well as participants with primary level of education remain those most affected by $S$. mansoni infection. Therefore, it is urgent to intervene systematically by treating infected persons, adopting a policy of cleaning up streams with molluscicides and increasing the purveyance of potable water to populations as well as mass educated population on their behavior toward water resources where they carry their different activities.

\section{References}

[1] Wieckzorek A. 2012. Les schistosomoses d'importation en France métropolitaine illustrées par des cas cliniques du C. H. U. de Nancy. Thèse présentée et soutenue publiquement pour obtenir le Diplôme d'Etat de Docteur en Pharmacie, Université de Nancy, France, 1-148.

[2] Zhang Y, Koukounari A, Kabaterine N, Fleming F, Kazibwe F, Tukahebwa E, Stohard R, Webster JP, Fenwick A. 2007. Parasitological impact of 2-year preventive chemotherapy on schistosomiasis and soil-transmitted helminth in Uganda. BMC Medecine 5, 27-43.

[3] Sara EB, Erick MM, Susan PM, Keziah O, Pauline MNM, Evan WS and Diana MSK. 2012. Mechanism of anemia in schistosoma mansoni infected school children in Western Kenya. American Journal Tropical Medicin Hygiene 87 (5), 862-867.

[4] Senghor B, Diallo A, Sylla NS, Doucouré S, Ndiath OM, Gaayeb L, Teukeng-Djuikwo FF, Bâ TC, Sokhna C. 2004. Prevalence and intensity of urinary schistosomiasis among children in the District of Niakhar, Region of Fatick, Senegal. Parasites and vectors 7, 1-6.

[5] Nkengazong L, Njiokou F, Asonganyi T. 2013. Two years impact of single praziquantel treatment on infection of urinary schistosomiasis in the Barombi Kotto focus, Cameroon. International Journal of Biosciences 3, 98- 107.

[6] King CH, Olbrych SK, Soon M, Singer ME, Carter J, Colley DG. 2011. Utility of repeated praziquantel dosing in the treatment of schistomiasis in high risk communities in Africa: a systematic review. PLoS Neglected Tropical Diseases 5, 115.

[7] Martyn T, Essame OS, Ratard RC. 2007. High risk behaviours and Schistosomiasis infection in Kumba, South-West Province, Cameroon. International Journal of Environmental Research and Public Health 4, 101-105.

[8] WHO 2006. Preventive Chemotherapy in human helminthiasis coordinated use of anthelminthic drugs in control intervention: a manual for health professionals and programme managers. Geneva: World Heath Oganization, 1-6.

[9] Yelnik A, Issoufa H, Apprious M, Tribouley J, Gentilini M, Ripert C. 1982. Etude épidémiologique de la bilharziose à $S$. haematobium dans le périmètre de Yagoua rizicole (Nord Cameroun). I. Prévalence de l'infestation et évaluation de la charge parasitaire. Bul Soc Pathol Exot Filiales, 75: 62-71.

[10] Kouodjip NL, Lehman LG, Bilong Bilong CF. 2012. Diagnostic des parasitoses intestinales à l'aide de la microscopie à fluorescence. Médecine Noire d'Afrique 59, 377-384.

[11] Tchuem Tchuenté LA, Behnke JM, Gilbert FS, Southgate VR, Vercruysse J. 2003. Polyparasitism with schistosoma haematobium and soil-transmitted helminth infections among school children in Loum, Cameroon. Tropical Medicine and International Health 8, 975-986. 
[12] Mazigo DH, Waihenya R, Mkoji MG, Zinga M, Ambrose EE, Jahanpour FO, Bahemana E, Mnyone LL, Kweka JE, Lwambo SJN. 2010. Intestinal schistosomiasis: prevalence, knowledge, attitude and practices among school children in an endemic area of North Western Tanzania. Journal of Rural and Tropical Public Health 9, 53 - 60.

[13] Sady H, Al-Mekhlafi MH, Mahdy KAM, Lim LAY, Mahmud R, Surin J. 2013. Prevalence and Associated Factors of Schistosomiasis among Children in Yemen: Implications for an Effective Control Programme. PLoS Neglected Tropical Diseases 7, 23-77.

[14] MINEPIA. 2013. Rapport sur le développement économique du Cameroun, Région du Littoral. Rapport de la mise en œuvre de la Stratégie de Croissance et l'Emploi dans le Littoral, p. 1-79.

[15] Gillespie TR. 2006. Non invasive assessment of gastrointestinal parasite infections in free-ranging primates. International Journal of Primatology 27, 1129-1143.

[16] Singh K, Muddasiru D. 2014. Epidemiology of schistosomiasis in school aged children in some riverine areas of Sokoto, Nigeria. Journal of Public Health and Epidemiology 6, 197-201.

[17] Massenet D, Jouanard N, Huttinger E. 2013. Évaluation de la technique de Kato-Katz pour la surveillance des infestations à Schistosoma mansoni en zone d'endémie. Annales de Biologie Clinique 71, 227-233.

[18] Njiokou F, Onguele R, Tchuem Tchuinté L, Kenmogne. 2004. Schistosomose urbaine au Cameroun. Etude longitudinale de la transmission dans un nouveau site d'extension du foyer de schistosomose intestinale de Melen, Yaoundé. Bulletin de la société et pathologie exotique 97, 37-40.

[19] Odiere RM, Rawago OF, Ombok M, Secor EW, Karanja MSD, Mwinzi NMP, Lamine JP, Won K. 2012. High prevalence of schistosomiasis in Mbita and its islands of Lake Victoria, Western Kenya. Parasites and vectors 5, 272-275.

[20] Sy I, Diawara L, Ngabo D, Barbier D, Dreyfuss G, Georges P. 2008. Schistosomiasis in school children in the Bandafassi region of East Senegal. Médecine Tropicale 68, 267-71.
[21] Ndamukong KJ, Ayuk MA, Dinga JS, Akenji TN, Ndiforchu VA, Titanji VP. 2001. Prevalence and intensity of urinary schistosomiasis in primary school children of the Kotto Barombi Health Area, Cameroon. East African Medical Journal 78, 287-289.

[22] Dramane Z. 2010. Etude comparative de la transmission de la schistosomiase (formes uro-génitale, intestinale et hépatique) dans dix sites du Burkina Faso. Thèse de Doctorat, Université unique d'Ouagadougou, Burkina Faso, 1- 111.

[23] Houmsou RS, Amuta EU, Sar TT. 2012. Profile of an epidemiological study of urinary schistosomiasis in two local government areas of Benue state, Nigeria. International Journal Medicine 1, 39-48.

[24] Kabiru M, Ikeh EI, Aziah I, Julia O, Fabiyi JP, Mohamed RA. 2013. Prevalence and intensity of schistosoma haematobium infections: A community based survey among school children and adults in Wamakko town, Sokoto state Nigeria. International Journal of Tropical Medicine and Public Health 2, 12-21.

[25] Risikat AS, Ayoade AA. 2012. Correlation analysis between the prevalence of schistosoma haematobuim and water conditions: A Case Study among the School Pupils in Southwestern Nigeria. International Journal of Recent Research and Applied Studies 13, 53-59.

[26] Anto F, Asoala V, Adjuik M, Anyorigiya T, Oduro A, Akazili J, Akweongo P, Bimi L, Hodgson A. 2014. Childhood Activities and Schistosomiasis Infection in the KassenaNankana District of Northern Ghana. Infectious Diseases and Therapy 2, 1-6.

[27] Gryseels B. 1984. La schistosomiase intestinale dans la plaine de la Ruzizi (Burundi): prospection préliminaire. Annales de la Société Belge de Médecine Tropicale 64, 249- 266.

[28] Ogbe GM. 1995. Schistosoma haematobium: A review of the relationship between prevalence, intensity and age. The Nigeria Journal of Parasitology 16, 39-46. 